\title{
A tale of two time zones: the impact of substitutes on cross-listed stock liquidity
}

\author{
Pamela C. Moulton \\ Li Wei ${ }^{*}$
}

JEL classification: F30 ; G14

Keywords: Substitutes; Cross-listing; Specialist; Liquidity externalities

\footnotetext{
${ }^{*}$ Moulton (contact author) is at Fordham Graduate School of Business, 113 West $60^{\text {th }}$ Street, New York, NY 10023; phone: (212) 636-6135; fax: (212) 765-5573; e-mail: pmoulton@fordham.edu. Wei is at Citigroup Global Capital Markets, 3 Garden Road, Citibank Tower, Central, Hong Kong; phone: (852) 2501-2303; e-mail: li.wei@citi.com. We thank an anonymous referee, Paul Bennett, Bruno Biais, Ekkehart Boehmer, Jay Coughenour, Bernard Dumas, Cheol Eun, Terry Hendershott, Joel Hasbrouck, Andrew Karolyi, Simi Kedia, Don Keim, Bruce Lehmann (the editor), Michael Melvin, Albert Menkveld, Tom O’Brien, Marios Panayides, Jörg Rocholl, Katharine Ross, Patrik Sandås, George Sofianos, Glen Surnamer, Jean Tobin, seminar participants at Fordham University and Rutgers University, and participants at the 2005 Financial Management Association meetings, the HEC Montreal International Conference on New Financial Market Structures, the 2005 Western Finance Association meetings, and the Wharton Conference on the Future of Cross-Border Equity Issuance and Trading for helpful comments. We thank Sachin Chincholi for excellent research assistance. We thank the New York Stock Exchange (NYSE) for providing data. Part of this research was conducted while Moulton and Wei were economists at the NYSE. The opinions expressed in this paper do not necessarily reflect the opinions of the members, officers, or employees of the NYSE.
} 


\begin{abstract}
This article examines how the market quality of European cross-listed stocks is affected by the partial-day availability of close substitutes, i.e., shares of the same companies that are traded in their home markets but are not fully fungible with the cross-listed shares. Our findings suggest that narrower spreads and more competitive liquidity provision during overlapping trading hours reflect a significant impact from the availability of more substitutes in addition to the enhanced information environment and liquidity externalities when home markets are open. Our results also provide a richer picture of specialists' intraday activities and offer new evidence of market integration.
\end{abstract}


In an integrated market environment, a cross-listed stock’s trading should be influenced by activity in its home-market counterpart. ${ }^{1}$ Furthermore, many U.S. investors view home-market shares as potential substitutes for cross-listed stocks, the traditional vehicle for international diversification (JPMorgan, 2003). A natural question for investors and researchers is how cross-listed stock trading is affected by the availability of home-market substitutes when cross-listing and home markets are both open (overlapping trading hours).

Hagerty (1991) predicts that increasing the number of substitute assets in a market reduces a liquidity provider's ability to set wide spreads and thus improves market quality. Sengupta (2005) derives an analogous prediction for substitute assets trading in different markets: He predicts that the competition from liquidity providers in the home market limits the ability of liquidity providers in a cross-listing market to set wide spreads. Both models presume the existence of close substitute assets, while empirical work shows that stocks of different firms even in the same industry and sharing other fundamental characteristics are generally imperfect substitutes (e.g., Shleifer, 1986; Beneish and Whaley, 1996; and Lynch and Mendenhall, 1997). In this paper, we use cross-listed stocks and their home-market counterparts, which are closer to perfect substitutes although not fully fungible, to study the impact of substitutes on stock trading. In particular, we analyze transaction costs, displayed liquidity, and the behavior of the New York Stock Exchange (NYSE) specialists for European crosslisted stocks during overlapping trading hours and nonoverlapping trading hours (when only the NYSE is open), to determine empirically how the availability of more substitutes affects stock trading. We also examine to what extent these effects are distinct from the effects of heightened information production and positive liquidity externalities during overlapping trading hours.

European cross-listed stocks offer several advantages for analyzing how the availability of substitutes affects liquidity provision and trading. European market trading hours partially overlap

\footnotetext{
${ }^{1}$ Karolyi (2006) documents that there are 2,300 cross-listed stocks worldwide. The cross-listed stocks of 467 companies accounted for $10.2 \%$ of NYSE trading volume in 2003, with the largest trading share coming from European companies. Cross-listed stock trading has been increasing as a percentage of overall stock trading on the NYSE since 2003. For a theoretical analysis of why companies choose to cross-list, see, for example, Foucault and Gehrig (2008).
} 
U.S. market trading hours, so we can observe cross-listed stocks trading daily with and without homemarket substitutes available. Most European cross-listed stocks are from developed home markets, and investor surveys find that cross-listed and home-market stocks from developed markets are generally viewed as substitutes, while emerging-market stocks are less likely to be viewed as substitutes for their cross-listed counterparts (JPMorgan, 2003). Finally, the universe of European cross-listed stocks includes thinly traded as well as actively traded stocks, allowing us to analyze a broad cross-section of firms.

Our study reveals many differences in cross-listed stock trading when home markets are open versus when they are not. We find that European cross-listed stock spreads are significantly lower during overlapping trading hours than during nonoverlapping trading hours. We also find that quoted depth, comprising displayed liquidity from public limit orders, floor brokers, and the specialist, is significantly greater during overlapping than during nonoverlapping trading hours. ${ }^{2}$ In addition to more liquidity being displayed during overlapping trading hours, we find that the specialist is significantly less active in European cross-listed stocks during overlapping trading hours. Further analysis shows that these results reflect the impact of an additional substitute asset improving market quality by increasing competition among liquidity providers, as predicted by Hagerty (1991) and Sengupta (2005), in addition to the heightened information production and positive liquidity externalities during overlapping trading hours.

This paper is related to research on the links between home-market and cross-listed stock trading. Domowitz, Glen, and Madhavan (1998) posit that even as markets become more accessible globally, the impact of home-market trading on cross-listed trading depends on the degree informational integration between the markets. Bacidore and Sofianos (2002) find that full-day transaction costs are higher for cross-listed stocks than for U.S. stocks, all else equal, because of the higher adverse selection and realized spreads in cross-listed stocks. Bacidore, Battalio, Galpin, and

\footnotetext{
${ }^{2}$ Our quoted depth results are consistent with the findings for European cross-listed stocks in Bacidore, Battalio, Galpin, and Jennings (2005), whose focus is how depth varies for cross-listed stocks from emerging versus developed markets.
} 
Jennings (2005) find that quoted depth is larger (smaller) for NYSE cross-listed stocks from developed (emerging) markets during overlapping trading hours. Sengupta (2005) finds that at the NYSE open quoted spreads are lower for actively-traded European cross-listed stocks, consistent with Howe and Ragan's (2002) finding that at the NYSE open volatility is lower for European cross-listed stocks than

for U.S. stocks. Both papers suggest that home-market trading influences European cross-listed stock trading at the NYSE open.

Our paper presents the first study that examines intraday liquidity provision and transaction costs together, highlighting the effects of competitive liquidity provision for substitute securities on market quality throughout the trading day, not only at the open. Our focus on how the competition from home-market substitutes affects liquidity provision in cross-listed stocks also reveals a previously unexplored richness in the specialist's intraday role. We find that the specialist's higher overall participation in cross-listed versus U.S. stock trading, documented in Bacidore and Sofianos (2002), is comprised of lower participation during overlapping trading hours and higher participation after European markets close, at least in part reflecting changes in the competition among liquidity providers.

The organization of the paper is as follows. Section 1 provides a review of related literature and discussion of cross-listed and home-market stock substitutability. Section 2 discusses the data and methodology. Section 3 presents our key empirical findings and relates them to theoretical predictions. Section 4 concludes.

\section{Background}

\subsection{Research on substitute assets and on cross-listed stock trading}

Our main theoretical motivation comes from Hagerty (1991) and Sengupta (2005). Hagerty models bid-ask spreads in markets with multiple assets and shows that a liquidity provider's ability to set wide spreads is limited by the existence of substitutes in the same market. Hagerty finds that increasing the number of substitutes lowers the equilibrium spread for an asset because liquidity 
providers compete for demand from traders choosing between substitute assets. Sengupta (2005) extends this intuition to competing markets and finds analogously that intermarket competition from home-market shares should lower spreads for cross-listed stocks. Parlour and Seppi (2003) examine a richer model of intermarket competition for substitutes. They find that competition between a pure limit order market (like most European exchanges) and a hybrid market with both a specialist and a limit order book (like the NYSE) can lead to either better or worse market quality than a hybrid market trading alone, depending on traders’ order preferencing rules, which are not readily observable.

Domowitz, Glen, and Madhavan (1998) predict that the market quality of cross-listed stocks depends on the degree to which home and cross-listing markets are linked informationally. If markets are sufficiently segmented informationally, trading costs are higher for cross-listed stocks because of the greater adverse selection arising from the existence of arbitrageurs who exploit pricing differences between the home and cross-listing markets at the expense of liquidity providers in the cross-listing market. Building on the intuition of Domowitz, Glen, and Madhavan (1998), Bacidore and Sofianos (2002) examine how the intrinsic differences between U.S. and cross-listed stocks affect the market quality and specialist activity in cross-listed stocks relative to U.S. stocks. Focusing on full-day trading activity, they find higher adverse selection in cross-listed stocks, which leads to wider spreads and lower specialist inventory positions in cross-listed stocks compared to U.S. stocks. While Bacidore and Sofianos (2002) acknowledge the importance of whether the home and cross-listing markets’ trading hours overlap, they do not examine intraday changes.

Several empirical studies document that trading volume and volatility are generally higher for cross-listed stocks from developed markets when their home markets are open (e.g., Howe and Ragan, 2002; and Menkveld, 2008). Higher volume during overlapping trading hours is attributed to the tendency of traders to cluster in time, as in Admati and Pfleiderer (1988), and arbitrage and ordersplitting across markets, as modeled in Chowdhry and Nanda (1991) and Menkveld (2008).

Also related to our work are studies linking the higher volatility of cross-listed stocks when their home markets are open to greater price discovery in the richer information environment of 
overlapping trading hours. Studies largely agree that for firms from developed home markets, information production and price discovery are greater when cross-listing and home markets are both open (e.g., Werner and Kleidon, 1996; Grammig, Melvin, and Schlag, 2005a; Menkveld, Koopman, and Lucas, 2006; Pascual, Pascual-Fuster, and Climent, 2006; and Phylaktis and Korczak, 2006). In the present study, we investigate whether cross-listed stock trading is affected by the availability of home-market substitutes beyond the effects of the enhanced information environment.

A growing body of research shows that cross-listed and home-market shares generally trade near price parity, adjusted for conversion costs [e.g., Eun and Sabherwal (2003) on Canadian stocks, Grammig, Melvin, and Schlag (2005b) on British, Canadian, French, and German stocks, and Phylaktis and Korczak (2006) on British and French stocks]. In one of the most comprehensive studies to date, Gagnon and Karolyi (2004) examine cross-listed and home-market stock pairs from 39 countries and find that price discrepancies are small on average, are most extreme in emerging markets, and are generally reversed within one day, suggesting that active arbitrageurs enforce parity. These findings suggest that global market integration has increased significantly since Werner and Kleidon's (1996) finding that the NYSE and the LSE were not integrated in 1991. Price parity between European cross-listed and home-market stocks is also a natural requirement for, and perhaps evidence of, traders' considering them substitutes for each other.

\subsection{Cross-listed stocks and home-market stocks as substitutes}

Cross-listed stocks and their home-market counterparts represent equity exposure to the same firm and thus should be closer substitutes than, for example, the domestic shares of two different firms in the same industry. But home-market and cross-listed shares are distinct securities and are not fully fungible, so they are not perfect substitutes. There are three main types of cross-listed stocks traded on the NYSE, and they differ in how close they are to being fully fungible with their home-market 
stocks. $^{3}$

Most cross-listed stocks on the NYSE are American Depositary Receipts (ADRs). ADRs are derivative instruments backed by home-market shares. To create ADRs, a depositary bank buys homemarket shares, places them with a custodian, and issues new dollar-denominated certificates. ADRs and home-market shares are not fungible: Different securities are traded in the U.S. and the home market, and the depositary bank charges a conversion fee to switch between them. Individual countries can also tax conversions. A notable example is the United Kingdom, which levies a 150 basis point Stamp Duty Reserve Tax on each British common share that is transferred to an ADR.

New York Registered Shares (NY Shares) are U.S. dollar-denominated certificates issued by (mostly Dutch) companies specifically for the U.S. market. NY Shares represent direct claims on the company; they are not derivative securities like ADRs. But as with ADRs, NY Shares are not fungible with home-market shares and holders must pay a conversion fee to switch between them.

Global Shares are a single class of ordinary shares trading on both the NYSE and the home market. The certificate traded on the NYSE is indistinguishable from that traded on the home market, both represent direct claims on the company, and there are no conversion fees. Nonetheless, Global Shares are not fully fungible, since investors buying Global Shares on the NYSE (home market) must hold them in U.S. dollars (home currency) and receive U.S. dollar (home currency) dividends.

A recent survey reveals that many institutional investors view cross-listed stocks and homemarket stocks from developed markets as substitutes (JPMorgan, 2003). A third of the surveyed investors say they would buy either instrument depending on relative liquidity and pricing or are indifferent between the two instruments. The one-third of respondents who prefer home-market stocks cite the broader array of companies available and greater liquidity, while the one-third who prefer cross-listed stocks cite lower holding costs and lower risk, particularly for emerging market stocks.

\footnotetext{
${ }^{3}$ For a more detailed discussion of cross-listed securities' fungibility see Foerster and Karolyi (1999) and Pulatkonak and Sofianos (1999). For a description of the mechanics of arbitraging cross-listed and home-market stocks, see Gagnon and Karolyi (2004).
} 


\section{Data and Methodology}

\subsection{Sample construction and descriptive statistics}

There are 186 European stocks cross-listed on the NYSE as of year-end 2003, according to the NYSE Non-U.S. Companies database. We eliminate 18 stocks that do not have information available from the CRSP database, 12 that have no home-market listing, 11 whose home-market trading hours do not overlap NYSE trading hours, four that split, three that are newly listed during 2003, two with changes in their ADR ratios, and one with only one trade in 2003. The remaining 135 stocks constitute our European cross-listed sample. ${ }^{4}$ The sample comprises 122 ADRs, nine NY Shares, and four Global Shares. On average in 2003, 7.2\% of the companies' global equity trading volume occurs in the U.S., with a range of less than $1 \%$ to more than $99 \%{ }^{5}$ Figure 1 shows the sample distribution across the 14 European home exchanges and the overlap between European exchanges and NYSE trading hours.

\section{[Figure 1 Here]}

We construct a matched sample of U.S. domestic stocks listed on the NYSE for the 135 European cross-listed stocks. From the universe of U.S. stocks, we first eliminate stocks that are crosslisted on European exchanges and stocks that split during 2003. We then use CRSP data to determine a unique match for each stock in our European sample based on NYSE daily price, volatility, and volume during 2003. ${ }^{6}$ For each European stock, we choose the U.S. domestic stock that minimizes the

\footnotetext{
${ }^{4}$ Although some of these stocks are thinly traded, as detailed in Table 1, excluding stocks with five or fewer trades per day on average yields qualitatively similar results, so we present only the full-sample results.

${ }^{5}$ About half of the sample stocks are cross-listed in one or more other countries in addition to the U.S. Such "third-market" listings should not significantly affect our results, as most of the third-market listings are in other European markets with similar trading hours to the home markets. For the average sample stock, $4 \%$ of its global trading volume occurs in European markets outside its home market and $0.1 \%$ of its global trading volume occurs in Asian markets in 2003. Our results are robust to the exclusion of stocks with third-market listings.

${ }^{6}$ We use volume rather than market capitalization in our matching criteria because we find inconsistencies in CRSP market capitalization for cross-listed stocks: CRSP market capitalization appears to reflect the entire global equity for some firms but only the cross-listed equity for other firms. Our results do not appear to be driven by our choice of matching criteria or the differences in matching variables for the pairs selected. Regression analysis of our results on the differences in our matching variables (price, volatility, and volume), difference in CRSP market capitalization, and difference in intraday volume changes shows that these factors do not explain our results. We also analyze an alternative matched sample of U.S. stocks chosen based on price, volatility, and global (rather than NYSE only) volume. Intraday patterns of transaction costs and liquidity provision for this alternative matched sample are qualitatively similar to our original matched sample results and yield identical inference. Detailed results of all robustness checks are available on request.
} 
matching score (p-score):

$$
\text { p-score }=\frac{\sum_{i=1}^{3}\left|\left(\frac{X_{i}^{\text {US }}}{X_{i}^{\text {Eur }}}-1\right)\right|}{3} \text {, }
$$

where $\mathrm{X}_{i}^{U S}$ denotes the value of the $i$ th matching variable for the U.S. stock, and $\mathrm{X}_{i}^{\text {Eur }}$ denotes the value of the $i$ th matching variable for the European stock. The mean p-score for the matches is 0.14 , with a median of 0.11 .

We also construct four other cross-listed stock samples. Starting with the NYSE Non-U.S. Companies database and eliminating stocks that split, change symbol, have no home listing, or are listed for only part of the year, we obtain samples of 69 Asian, 66 Canadian, and 64 Latin American cross-listed stocks. ${ }^{7}$ Table 1 presents descriptive statistics for all five samples during the entire NYSE trading day.

\section{[Table 1 Here]}

The main sample period for our analysis is the 221 days in 2003 on which the NYSE and all 14 European home exchanges were open for full trading days, excluding the week between the change to daylight savings time in Europe and the U.S. We also examine the holidays on which the home exchanges are closed and the NYSE is open. The number of home-exchange holidays on which the NYSE is open ranges from two to ten, averaging four days for the European cross-listed sample.

\subsection{Data and measures}

We use data from the NYSE Consolidated Trade (CT), Consolidated Quote (CQ), Specialist Equity Trade (SPET), and System Order Data (SOD) files. After filtering these data to remove bad trades and quotes, ${ }^{8}$ we construct several measures of trading activity, transaction costs, and liquidity

\footnotetext{
${ }^{7}$ About $40 \%$ of the Asian cross-listed stocks and a quarter of the Canadian and Latin American cross-listed stocks are also cross-listed on European exchanges, but these third-market listings account for less than $1 \%$ of global trading volume on average in 2003.

${ }^{8}$ We use regular NYSE trade records, filtering out cancels, errors, late reports, bunched, bunched sold, and average-price transactions. We also exclude trades with price or size equal to zero and trades with price changes of $20 \%$ or more from the previous trade. These filters remove less than $0.3 \%$ of the original trade records. We
} 
provision.

To summarize trading activity, we examine each stock’s average volume, number of trades, and intraday volatility. The volatility measure, the intraday relative range volatility, is defined as the five-minute high-low range divided by the last transaction price in the interval. We also calculate volatility measured as the standard deviation of five-minute midquote returns as a robustness check.

We focus on quoted and effective spreads to assess trading costs. We calculate percentage spreads to control for any effects caused purely by stock price differences. The percentage quoted spread is the difference between the best offer and the best bid price, divided by the quote midpoint.

The percentage effective spread is defined as:

$$
\text { Percentage Effective } \text { Spread }_{t}=2 I\left(P_{t}-M_{t}\right) / P_{t} \text {, }
$$

where $I$ is an indicator variable that equals one for buyer-initiated trades and negative one for sellerinitiated trades, $P_{t}$ is the trade price, and $M_{t}$ is the quote midpoint at the time of the trade. We categorize trades as buyer-initiated (seller-initiated) if they occur above (below) the prevailing quote midpoint; trades occurring at the quote midpoint are categorized using the Lee and Ready (1991) algorithm. We use contemporaneous quotes to sign trades; see Bessembinder (2003). ${ }^{9}$ The effective spread captures the immediate price impact of a trade.

We further decompose the effective spread into the realized spread and the information content of the trade. The percentage realized spread is defined as:

$$
\text { Percentage Realized Spread }{ }_{t}=2 I\left(P_{t}-M_{t+5}\right) / P_{t} \text {, }
$$

where $M_{t+5}$ is the quote midpoint five minutes after the trade. We also calculate realized spreads using the quote midpoint 30 minutes after the trade and using the next day's opening price, as robustness

use regular NYSE quote records, filtering out quotes that are indicated to be errors, related to special mode conditions, and locked or crossed bid and ask. We also exclude quotes with zero or missing bid or ask prices or depth, quotes that change $20 \%$ or more from the previous quote, and quotes whose spread exceeds $20 \%$ of the quote midpoint. These filters remove less than $0.1 \%$ of the quote records. To reduce the quote data to a manageable size, we keep only the first quote in each second.

${ }^{9}$ While possible misclassification of trades could influence our spread estimates, any resulting bias should be less of a concern for comparing differences in spreads intraday and between different stock samples. Indeed, if the bias is constant intraday and across samples, our estimates of differences are unbiased. 
checks. The realized spread measures the price reversal after a trade, approximating the liquidity provider's profit net of the trade’s price impact.

The difference between the effective spread (what liquidity demanders pay) and the realized spread (what liquidity providers earn) is used as a measure of the information content of a trade. The information content is equal to the signed difference between the quote midpoints at the time of the trade and five minutes after the trade, as a percentage of the trade price.

We focus on quoted depth and the specialist participation rate to capture liquidity provision. The quoted depth includes liquidity displayed by public limit orders, floor brokers, and the specialist, and is calculated as the average depth at the NYSE best bid and best offer. Within this group of participants, the specialist is often considered the liquidity provider of last resort because of his affirmative obligation to ensure a "fair and orderly" market (NYSE, 1999, Rule 104) and his unique ability to observe and react quickly to activity on the trading floor and incoming electronic orders (see Panayides, 2007). These structural advantages that accrue to the specialist likely make him the most important liquidity provider trading a stock, although he is not the only liquidity provider. Boehmer and $\mathrm{Wu}$ (2006) find positive correlations among the signed trading activity of liquidity providers on the NYSE. We define the specialist participation rate as the sum of specialist purchase volume and sale volume, divided by total trading volume. ${ }^{10}$

\section{Results}

This section first presents our main analysis of how European cross-listed stocks trade on the NYSE when their home markets are open versus when they are closed. Second, it explores to what extent the availability of substitutes and the enhanced information environment, which are both related to home-market trading, explain our findings. Third, it examines whether factors unrelated to homemarket trading, such as time-of-day effects and cross-listed stock characteristics, explain our findings.

\footnotetext{
${ }^{10}$ The NYSE reports the specialist participation rate as the sum of specialist purchases and sales divided by total purchases and sales (twice total volume). We use single-counted volume in the denominator to be consistent with prior work such as Bacidore and Sofianos (2002) and Madhavan and Sofianos (1998).
} 


\subsection{Overlapping versus nonoverlapping trading in European cross-listed stocks}

We examine differences in trading activity, transaction costs, and liquidity provision for European cross-listed stocks on the NYSE between trading hours when their home exchanges are open (overlapping period) and when their home exchanges are closed (nonoverlapping period). The overlapping period for each cross-listed stock extends from the NYSE open at 9:30 a.m. EST until the cross-listed stock's home exchange closes. We define the nonoverlapping period to be an equal-length period beginning immediately after the home exchange closes. For example, for a cross-listed stock whose home exchange is the LSE, the overlapping period is 9:30 a.m. to 11:35 a.m. and the nonoverlapping period is 11:35:01 a.m. to 1:40 p.m. EST. We choose equal-length overlapping and nonoverlapping periods in the spirit of an event study, where our event is the daily closing of a crosslisted stock's home exchange. Our results are robust to alternative intraday-period definitions. ${ }^{11}$

We calculate trading activity, transaction cost, and liquidity provision measures for the overlapping and the non-overlapping period for each stock on each day, applying the same overlapping and nonoverlapping periods to each matched pair of stocks. Overlapping and nonoverlapping averages are then calculated for each stock across the 221 sample days, and crosssectional means, mean differences, and matched-pair difference-of-differences are reported in Table 2. We conduct significance tests on relative differences (taking the logarithm of each measure before computing standard errors and conducting the t-test for a difference in means) to address issues of heteroscedasticity in this and subsequent tables. For ease of interpretation, we report the actual means. Nonparametric tests on median differences yield identical inferences and are available on request.

\section{[Table 2 Here]}

Panel A of Table 2 compares intraday trading activity for the European and U.S. matched

\footnotetext{
${ }^{11}$ When we define the nonoverlapping period to include the remainder of the NYSE trading day, rather than to match the length of the overlapping period, we find qualitatively similar results. When we exclude the first 15 minutes of NYSE trading, reduce the intraday periods to 30 minutes before and after the home exchange closes, or exclude the 15 minutes before and after the home exchange closes, we find qualitatively similar results. The results are also qualitatively similar when we exclude the 11 European cross-listed stocks with less than two hours of overlap with their home exchanges.
} 
samples. As in previous studies, we find that both samples have higher share volume and volatility during overlapping trading hours. ${ }^{12}$ This evidence is consistent with the effects of arbitrage trading, order splitting, and heightened information production during overlapping trading hours.

Panel B of Table 2 analyzes how transaction costs differ during overlapping and nonoverlapping trading hours. We know from Bacidore and Sofianos (2002) that cross-listed stocks generally have higher transaction costs in full-day trading than U.S. stocks, all else equal. Thus we are not surprised to find significantly higher spreads for European cross-listed stocks than their U.S. matches in both intraday periods. ${ }^{13}$ Our novel finding is that quoted and effective spreads for the European cross-listed sample are significantly lower during the overlapping period than during the nonoverlapping period. ${ }^{14}$ Lower spreads during the overlapping period may be due to the availability of a home-market substitute and/or greater information production and price discovery lowering the adverse selection risk, since U.S.-based traders can observe home-market quotes during overlapping trading hours. In contrast, quoted and effective spreads for the U.S. matched sample are significantly higher during the overlapping period than during the nonoverlapping period, reflecting the well-known intraday pattern of U.S. stocks.

Panel C of Table 2 analyzes how liquidity provision differs in overlapping and nonoverlapping trading hours. Quoted depth is significantly higher in overlapping than in nonoverlapping periods for the European cross-listed stocks, which likely reflects greater competition among liquidity providers. ${ }^{15}$ In contrast, quoted depth is significantly lower in overlapping than in nonoverlapping periods for the U.S. stocks. We find that the specialist participation rate is sharply lower for European cross-listed stocks during overlapping trading hours, consistent with the notion

\footnotetext{
12 These results are qualitatively similar for both the intraday relative range volatility reported here and the volatility measured as the standard deviation of five-minute midquote returns; results are available on request.

${ }^{13}$ Similar results obtain for full-day transaction costs in our sample; results available on request.

${ }^{14}$ Volume-weighted effective spreads are reported in Table 2. Trade-weighted spreads lead to identical inference; results are available on request.

${ }^{15}$ Our study measures displayed liquidity only, but Bacidore, Battalio, Galpin, and Jennings (2005) find that undisplayed liquidity (provided by floor brokers and the specialist on the floor, not displayed in the quoted depth) is unchanged for European cross-listed stocks in overlapping versus nonoverlapping trading hours.
} 
that the specialist is less active when liquidity provision is more competitive during overlapping trading hours. In contrast, the U.S. matched stocks exhibit a higher specialist participation rate during the overlapping period. ${ }^{16}$

Taken together, these results show that transaction costs and liquidity provision differ dramatically for European cross-listed stocks when their home markets are open versus when they are closed.

\subsection{Explanations related to home-market trading}

There are two main theories of how European cross-listed stock trading may be affected by home-market trading during overlapping trading hours. First, Hagerty (1991) and Sengupta (2005) suggest that increasing the number of substitutes lowers the equilibrium spread for an asset because liquidity providers compete for demand from traders choosing between substitute assets. Since institutional investors generally view home-market stocks from developed markets as substitutes for cross-listed stocks, this theory predicts lower spreads and lower specialist participation rates as specialists face greater competition from other liquidity providers during overlapping trading hours.

Second, many studies find that for firms from developed home markets, overlapping trading hours are characterized by greater information production and price discovery (e.g., Grammig, Melvin, and Schlag, 2005a; Menkveld, Koopman, and Lucas, 2006; and Phylaktis and Korczak, 2006), which are likely to lead to positive liquidity externalities. In models such as Admati and Pfleiderer (1988) liquidity externalities arise when traders come together to reduce search and trading costs, including adverse selection, or the risk of trading against more informed counterparties. In European cross-listed stocks, such liquidity externalities may arise with greater information production because the global pool of traders is larger or because traders concentrate their trades during overlapping trading hours. Positive liquidity externalities predict lower spreads and lower specialist participation rates, because

\footnotetext{
${ }^{16}$ The difference in specialist participation rate changes does not appear to be due to the NYSE's Price Continuity Rule (PCR), part of the specialist's affirmative obligation (see Panayides, 2007). The PCR binds virtually the same amount of time during the overlapping and nonoverlapping periods: about $6 \%$ of the time for the European cross-listed stocks and about $7 \%$ of the time for the U.S. matched sample.
} 
there is less need for the specialist to act as liquidity provider of last resort when information asymmetries are lower, during overlapping trading hours.

Thus both the availability of home-market substitutes and the enhanced information environment could lead to lower transaction costs and lower specialist participation rates during overlapping trading hours. In this section we attempt to disentangle these two potential explanations by examining effective spread decompositions and cross-sectional stock differences. ${ }^{17}$

We first examine to what extent the intraday changes in effective spreads for European crosslisted stocks can be attributed to (i) changes in competition among liquidity providers, reflecting the impact of increased substitute availability (as in Hagerty, 1991), versus (ii) changes in the information content of trades, reflecting adverse-selection-based liquidity externalities (as in Admati and Pfleiderer, 1988). In Table 3, we decompose the effective spread results from Table 2 into two parts: the realized spread, which approximates a liquidity provider's profit and should reflect the impact of the additional substitutes, and the information content of a trade, which approximates the adverse selection in a trade and should reflect liquidity externalities. We know from Bacidore and Sofianos (2002) that cross-listed stocks generally have higher realized spreads and information content in fullday trading than U.S. stocks, all else equal. Thus we are not surprised to find significantly higher realized spreads for European cross-listed stocks than their U.S. matches in both intraday periods. But Table 3 also shows that realized spreads are significantly lower for European cross-listed stocks when their home markets are open than when they are closed, ${ }^{18}$ consistent with Hagerty’s (1991) and Sengupta's (2005) predictions that liquidity provider profits should be lower when more substitutes

\footnotetext{
${ }^{17}$ A third possible explanation is that liquidity providers quote tighter spreads during overlapping trading hours because they can hedge their cross-listed stock positions with home-market shares. Unfortunately, we are unable to observe the trading activity of specialists or other market makers in European markets. Analysis of specialist inventories on the NYSE shows that they do not take larger cross-listed stock positions during overlapping trading hours than during nonoverlapping trading hours, nor do specialists take larger positions in cross-listed stocks than in the matched U.S. stocks during overlapping trading hours. Both findings suggest that hedging with home-market shares is not a major contributor to cross-listed stock liquidity during overlapping trading hours.

${ }^{18}$ Realized spreads and information content based on the quote midpoint five minutes after each trade are reported in Table 3. Alternative measures of realized spreads and information content based on the quote midpoint 30 minutes after each trade and based on opening prices the following day are qualitatively similar and are available on request.
} 
are available. The information content of trades is also significantly lower for European cross-listed stocks when their home markets are open than when they are closed, suggesting that adverse-selectionbased liquidity externalities are present during overlapping trading hours. ${ }^{19}$

\section{[Table 3 Here]}

We next examine to what extent intraday changes in effective spreads and specialist participation rates are related cross-sectionally to the strength of a cross-listed stock's home-market substitute and its home-market information environment, to help us disentangle these two potential effects. We run the following cross-sectional regression, using annual averages for the dependent variables for each stock to reduce the noise of daily estimates. Robust standard errors control for heteroscedasticity, as in White (1980).

$$
\begin{aligned}
\text { IntradayDiff }_{i}= & \alpha+\beta \text { SubstituteStrength }_{i}+\gamma \text { InfoEnvironment } \\
i & +\chi \text { HomeMktSize }_{i} \\
& +\sum_{j=1}^{2} \delta_{j} \text { FirmCharacteristic }_{i, j}+\lambda \text { VolumeDifference }_{i} \\
& +\sum_{j=1}^{10} \phi_{j} \text { ControlVar }_{i, j}+\varepsilon_{i}
\end{aligned}
$$

where IntradayDiff is the overlap-nonoverlap difference in effective spread or participation rate for the European cross-listed stocks. As a proxy for the strength of the home-market substitute (SubstituteStrength), we use the percentage of a firm's global equity trading that occurs in Europe, because a more actively traded home-market stock is likely to be viewed as a more attractive substitute. ${ }^{20}$ As a proxy for the home-market information environment (InfoEnvironment), we use an index of home-market development, calculated as the natural logarithm of the product of the shareholder rights index from Bhattacharya and Daouk (2002) and the rule of law index and the

19 This finding echoes Barclay and Hendershott's (2004) finding that adverse-selection-based liquidity externalities lead to lower information content for regular-hours than for after-hours trades in U.S. stocks.

${ }^{20}$ We considered additional proxies for the strength of the home-market substitute, but none provided enough cross-sectional variation for powerful tests. For example, our sample includes three types of cross-listed shares, but 122 are ADRs versus only nine NY Shares and four Global Shares. We also investigated whether conversion costs vary across cross-listed shares, but we were informed by practitioners at two of the largest ADR depositary banks that conversion costs do not vary across stocks. 
accounting index from LaPorta, Lopez-de-Silanes, Shleifer, and Vishny (1998). ${ }^{21}$ These indices are often used to quantify differences in country development and are highly correlated with home-market transparency, a key factor in the information environment for cross-listed stocks (e.g., Eleswarapu and Venkataraman, 2006). As a country-level control, we include HomeMktSize, equal to the homeexchange market capitalization (that is, the market capitalization for all stocks traded on the home exchange). As controls for individual firm characteristics (FirmCharacteristic), we include the stock price and the firm's global market capitalization. In our extended specification, we include overlapping-nonoverlapping trading volume differences (VolumeDifference), as a proxy for liquidity externalities arising from concentrated trading during overlapping trading hours, ${ }^{22}$ and stock-level controls (ControlVar) for intraday differences in trade size, volatility, quoted depth, quoted spread, and specialist firms. ${ }^{23}$

\section{[Table 4 Here]}

Table 4 presents the results from our cross-sectional regressions of overlap-nonoverlap differences in effective spread and participation rate for the European cross-listed stocks. Each explanatory variable is scaled by its cross-sectional standard deviation, so coefficient estimates represent the change in the dependent variable for a one-standard-deviation change in the explanatory variable. Recall that the effective spread and participation rate differences are negative in the European cross-listed sample: Spreads are narrower and specialist participation rates are lower during overlapping trading hours. The effective spread difference is more negative for firms with more of their global trading in Europe, our proxy for the strength of the home-market substitute, even after

\footnotetext{
${ }^{21}$ Because the three market development indices are highly correlated for the European home markets, including the three measures as separate explanatory variables introduces considerable multicollinearity. Robustness checks using each index alone yield qualitatively similar results, available on request.

${ }^{22}$ Tests including the overlapping/nonoverlapping variance ratio as a proxy for the firm-specific information flow yield insignificant coefficients on the variance ratio variable, with other results qualitatively unchanged; results are available on request.

${ }^{23}$ Quoted spread differences are excluded from the effective spread difference regressions because including them would result in a test of price improvement (marginal change in effective spread relative to quoted spread), which is not the focus of the Hagerty (1991) or Sengupta (2005) predictions. Corwin (1999), Coughenour and Saad (2004), and Comerton-Forde, Hendershott, Jones, Moulton, and Seasholes (2008) show that NYSE specialists have a significant impact on execution costs and liquidity. We include as explanatory variables the five largest specialist firms; the other two firms each handle only two sample stocks.
} 
controlling for home-market and stock-level differences. A one-standard-deviation increase in the percentage of trading in Europe leads to about a five (six) basis point widening in the overlapnonoverlap effective spread difference in the basic (extended) specification, suggesting that the strength of the home-market substitute matters. We find weaker support for the role of the information environment in the effective spread regressions, as the coefficient estimate on home market development is significant in only our basic specification, and then only at the $10 \%$ level.

Specialist participation rate differences are also more negative for stocks with more of their global trading volume in Europe, consistent with the substitutes hypothesis. A one-standard-deviation increase in the percentage of trading in Europe leads to about a two (one) basis point widening in the overlap-nonoverlap participation rate difference in the basic (extended) specification. The participation rate regressions also offer support for the information/externality hypothesis, with the coefficient on home-market development (our proxy for the openness of the home-market information environment) negative and significant in both specifications. A one-standard-deviation increase in the home-market development leads to a nearly two basis point widening in the overlap-nonoverlap participation rate difference, suggesting that adverse-selection based liquidity externalities affect specialists’ liquidity provision in cross-listed stocks.

Collectively, these findings suggest that increased liquidity provider competition due to the availability of a home-market substitute contributes to the lower spreads and higher liquidity provision for European cross-listed stocks in overlapping trading hours, even after controlling for the enhanced information environment and potential liquidity externalities.

\subsection{Explanations unrelated to home-market trading}

In this section we consider two possible explanations for the intraday patterns of transaction costs and liquidity provision that are unrelated to whether European home markets are open or closed. First, because European home-exchange trading hours overlap the beginning of the NYSE trading day, the observed differences between overlapping and non-overlapping periods could simply be due to the 
time of day. The matched sample analysis in Table 2 suggests that time-of-day effects do not explain the European cross-listed sample results. All of the transaction cost and liquidity provision measures exhibit opposite-sign intraday differences in the U.S. matched and European cross-listed samples, leading to significant overlap-nonoverlap difference-of-differences, although both samples have higher volume and volatility during overlapping trading hours.

A second potential explanation for the transaction cost and liquidity provision changes documented in Table 2 is that these European cross-listed stocks or cross-listed stocks in general have certain characteristics other than their home-market trading hours that cause them to trade differently than U.S. domestic stocks. We explore these possibilities by examining the behavior of cross-listed stocks without overlapping trading hours: first, the European sample on home-exchange holidays; and second, other cross-listed samples with no overlapping or no nonoverlapping trading hours.

Table 5 examines the European cross-listed stocks and their U.S. matches on European market holidays. This analysis focuses on the cross-section of 135 stocks, as in the regular trading day analysis of Table 2, but the holiday average for each stock is estimated from far fewer observations (two to ten holidays, compared to 221 non-holidays). Both the European cross-listed stocks and the U.S. matches follow the usual intraday pattern of higher volume and volatility during the period when both markets are normally open, although overall volumes are lower than on days when all exchanges are open. But on days when European markets are closed, European cross-listed stock spreads are higher in the "overlapping” period than in the nonoverlapping period, mimicking the pattern exhibited by the U.S. matched stocks and in contrast to the pattern of European stocks on days when their home markets are open. Likewise, European cross-listed stocks and their U.S. matches both exhibit lower quoted depth and higher specialist participation rates during the "overlapping” period than in the nonoverlapping period, in contrast to the European cross-listed stocks’ higher quoted depth and lower specialist participation rates during the overlapping period on days when their home markets are open.

\section{[Table 5 Here]}

Table 6 analyzes trading, transaction costs, and liquidity provision for Asian, Canadian, and 
Latin American cross-listed stocks in the first versus second two hours of NYSE trading. Asian crosslisted stocks have no home-market trading during either two-hour period, while Canadian and Latin American cross-listed stocks have home-market shares trading during both two-hour periods. ${ }^{24}$ The non-European cross-listed stocks generally exhibit intraday patterns of transaction costs and liquidity provision more similar to the U.S. matched stocks than to the European cross-listed stocks: Spreads are higher, quoted depth is lower, and the specialist participation rate is higher during the first two hours of trading than during the second two hours, as is the case for the U.S. matched stocks.

\section{[Table 6 Here]}

These results suggest that characteristics of cross-listed stocks other than their overlapping trading hours with their home markets do not explain the intraday changes in transaction costs and liquidity provision for European cross-listed stocks.

\section{Conclusion}

We find that European cross-listed stock spreads are lower and quoted depth is higher during overlapping trading hours than during nonoverlapping trading hours. In addition to more liquidity being displayed during overlapping trading hours, the specialist is less active in European cross-listed stocks during overlapping trading hours, suggesting that greater competition squeezes out the specialist as a liquidity provider. Taken together, these results suggest that the availability of homemarket substitutes increases competition among liquidity providers, leading to lower spreads. The effects of additional substitute availability remain significant after controlling for the enhanced information environment and liquidity externalities that characterize overlapping trading hours.

Our findings suggest that there is a richer story behind the observation that specialists participate more in cross-listed stocks than in U.S. stocks. Although specialists are more active in European cross-listed stocks overall, they supply less liquidity when European markets are open.

\footnotetext{
${ }^{24}$ Although some of the Asian, Canadian, and Latin American cross-listed stocks are also cross-listed on European exchanges, these third-market listings account for less than $1 \%$ of global trading volume on average. Our results are robust to the exclusion of cross-listed stocks with third-market listings.
} 
Future work on specialists' intraday trading may further illuminate how and when designated market makers enhance the trading process, a question of growing importance as more exchanges introduce designated market makers for less liquid stocks (see Venkataraman and Waisburd, 2007).

Our results have potential implications for investors and cross-listing markets. Knowing how overlapping trading hours affect the liquidity of cross-listed stocks is valuable to investors choosing when to trade and to markets setting trading hours. Several U.S. markets are considering opening earlier in the morning, which would increase overlapping trading hours for many cross-listed stocks.

This work also offers broader perspectives on how the trading of one asset is affected by the availability of additional substitutes, which may not only further our understanding of cross-listed stocks and their substitutable home-market stocks but also offer insights into the success and failure of new securities and derivatives, such as single-stock futures. 


\section{References}

Admati, A., Pfleiderer, P., 1988. A theory of intraday patterns: volume and price variability. Review of Financial Studies 1, 3-40.

Bacidore, J., Battalio, R., Galpin, N., Jennings, R., 2005. Sources of liquidity for NYSE-listed nonU.S. stocks. Journal of Banking and Finance 29, 3075-3098.

Bacidore, J., Sofianos, G., 2002. Liquidity provision and specialist trading in NYSE-listed non-U.S. stocks. Journal of Financial Economics 63, 133-158.

Barclay, M., Hendershott, T., 2004. Liquidity externalities and adverse selection: evidence from trading after hours. Journal of Finance 59, 681-710.

Beneish, M., Whaley, R., 1996. An anatomy of the "S\&P Game”: The effects of changing the rules. Journal of Finance 51, 1909-1930.

Bessembinder, H., 2003. Issues in assessing trade execution costs. Journal of Financial Markets 6, 233-257.

Bhattacharya, U., Daouk, H., 2002. The world price of insider trading. Journal of Finance 57, 75-108.

Boehmer, E., Wu, J., 2006. Order flow and prices. Working paper, Texas A\&M University.

Chowdhry, B., Nanda, V., 1991. Multimarket trading and market liquidity. Review of Financial Studies 4, 483-511.

Comerton-Forde, C., Hendershott, T., Jones, C., Moulton, P., Seasholes, M., 2008. Time variation in liquidity: the role of market-maker inventories and liquidity. Journal of Finance forthcoming.

Corwin, S., 1999. Differences in trading behavior across NYSE specialist firms. Journal of Finance 54, 721-745.

Coughenour, J., Saad, M., 2004. Common market makers and commonality in liquidity. Journal of Financial Economics 73, 37-69.

Domowitz, I., Glen, J., Madhavan, A., 1998. International cross-listing and order-flow migration: evidence from an emerging market. Journal of Finance 53, 2001-2027.

Eleswarapu, V., Venkataraman, K., 2006. The impact of legal and political institutions on equity trading costs: a cross-country analysis. Review of Financial Studies 19, 1081-1111.

Eun, C., Sabherwal, S., 2003. Cross-border listings and price discovery: evidence from U.S.-listed Canadian stocks. Journal of Finance 58, 549-575.

Foerster, S., Karolyi, G., 1999. The effects of market segmentation and investor recognition on asset prices: evidence from foreign stock listing in the United States. Journal of Finance 54, 981-1013.

Foucault, T., Gehrig, T., 2008. Cross-listings, stock price informativeness, and investment decisions. Journal of Financial Economics 88, 146-168.

Gagnon, L., Karolyi, G., 2004. Multi-market trading and arbitrage. Working paper, Ohio State 
University.

Grammig, J., Melvin, M., Schlag, C., 2005a. Internationally cross-listed stock prices during overlapping trading hours: price discovery and exchange rate effects. Journal of Empirical Finance 12, 139-164.

Grammig, J., Melvin, M., Schlag, C., 2005b. The role of U.S. trading in pricing internationally crosslisted stocks. Working paper, Arizona State University.

Hagerty, K., 1991. Equilibrium bid-ask spreads in markets with multiple assets. Review of Economic Studies 58, 237-258.

Howe, J., Ragan, K., 2002. Price discovery and the international flow of information. Journal of International Financial Markets, Institutions and Money 12, 201-215.

Ji, S., 2006. Does investor base influence stock comovement? Working paper, Baruch College.

JPMorgan, 2003. Buy-side survey: ADR investing. www.adr.com, 15 pages.

Karolyi, G., 2006. The world of cross-listings and cross-listings of the world: challenging conventional wisdom. Review of Finance 10, 73-115.

La Porta, R., Lopez-de-Silanes, F., Shleifer, A., Vishny, R., 1998. Law and finance. Journal of Political Economy 106, 1113-1155.

Lee, C., Ready, M., 1991. Inferring trade direction from intraday data. Journal of Finance 46, 733746.

Lowengrub, P., Melvin, M., 2002. Before and after international cross-listing: an intraday examination of volume and volatility. Journal of International Financial Markets, Institutions \& Money 12, 139-155.

Lynch, A., Mendenhall, R., 1997. New evidence on stock price effects associated with changes in the S\&P 500 index. Journal of Business 70, 351-383.

Madhavan, A., Sofianos, G., 1998. An empirical analysis of NYSE specialist trading. Journal of Financial Economics 48, 189-210.

Menkveld, A., 2008. Splitting orders in overlapping markets: a study of cross-listed stocks. Journal of Financial Intermediation 17, 145-174.

Menkveld, A., Koopman, S., Lucas, A., 2006. Modeling round-the-clock price discovery for crosslisted stocks using state space methods. Journal of Business and Economic Statistics 25, 213-225.

NYSE, 1999. New York Stock Exchange, Inc. Constitution and Rules, vol. 2. CCH Incorporated, Chicago, IL.

Panayides, M., 2007. Affirmative obligations and market making with inventory. Journal of Financial Economics 86, 513-542.

Parlour, C., Seppi, D., 2003. Liquidity-based competition for order flow. Review of Financial Studies 
16, 301-343.

Pascual, R., Pascual-Fuster, B., Climent, F., 2006. Cross-listing, price discovery and the informativeness of the trading process. Journal of Financial Markets 9, 144-161.

Phylaktis, K., Korczak, P., 2006. Specialist trading and the price discovery process of NYSE-listed Non-US stocks. Working paper, City University London.

Pulatkonak, M., Sofianos, G., 1999. The distribution of global trading in NYSE-listed non-U.S. stocks. Working paper, New York Stock Exchange.

Sengupta, S., 2005. Implications of European trading for the New York Stock Exchange open. Working paper, Arizona State University.

Shleifer, A., 1986. Do demand curves for stocks slope down? Journal of Finance 41, 579-590.

Venkataraman, K., Waisburd, A., 2007. The value of a designated market maker. Journal of Financial and Quantitative Analysis 42, 735-758.

Werner, I., Kleidon, A., 1996. U.K. and U.S. trading of British cross-listed stocks: An intraday analysis of market integration. Review of Financial Studies 9, 619-664.

White, H., 1980. A heteroskedasticity-consistent covariance matrix estimator and a direct test of heteroskedasticity. Econometrica 48, 817-838. 


\section{Table 1: Sample summary statistics}

This table contains summary statistics based on full-day trading for five samples of stocks: European cross-listed stocks (CLS), matched U.S. domestic stocks, and Asian, Canadian, and Latin American cross-listed stocks. The European CLS and U.S. Match stocks are matched based on price, volatility, and volume. Averages for each stock are calculated over 221 days in 2003, and statistics are calculated across sample stocks using data from the NYSE CT and Non-U.S. Companies databases. All measures are based on the full trading day.

\begin{tabular}{|c|c|c|c|c|c|c|}
\hline & & $\begin{array}{r}\text { European } \\
\text { CLS }\end{array}$ & $\begin{array}{r}\text { U.S. } \\
\text { Match }\end{array}$ & $\begin{array}{r}\text { Asian } \\
\text { CLS }\end{array}$ & $\begin{array}{r}\text { Canadian } \\
\text { CLS }\end{array}$ & $\begin{array}{r}\text { Latin American } \\
\text { CLS }\end{array}$ \\
\hline \multirow[t]{4}{*}{ Price (\$) } & Mean & 24.40 & 23.06 & 22.97 & 21.97 & 14.54 \\
\hline & Median & 20.08 & 20.11 & 19.19 & 18.83 & 12.51 \\
\hline & Min & 2.16 & 2.27 & 2.17 & 3.23 & 1.03 \\
\hline & $\operatorname{Max}$ & 93.47 & 80.33 & 102.26 & 68.27 & 41.19 \\
\hline \multirow[t]{4}{*}{ Daily High-Low Volatility (\%) } & Mean & 2.04 & 2.12 & 1.85 & 2.18 & 2.43 \\
\hline & Median & 1.93 & 1.96 & 1.76 & 1.99 & 2.15 \\
\hline & Min & 0.32 & 0.69 & 0.33 & 1.11 & 0.51 \\
\hline & Max & 6.51 & 5.91 & 6.78 & 4.16 & 6.70 \\
\hline \multirow[t]{4}{*}{ Daily Volume (shares) } & Mean & 305,162 & 287,041 & 277,925 & 498,730 & 165,657 \\
\hline & Median & 40,874 & 45,301 & 53,454 & 66,189 & 42,683 \\
\hline & Min & 1,117 & 1,047 & 775 & 2,137 & 1,271 \\
\hline & Max & $9,633,867$ & $9,400,057$ & $6,067,490$ & $15,729,255$ & $1,617,251$ \\
\hline \multirow[t]{4}{*}{ Daily Volume (\$) } & Mean & $7,551,603$ & $7,224,095$ & $4,085,730$ & $6,668,275$ & $3,252,378$ \\
\hline & Median & 830,510 & 767,252 & $1,374,200$ & $1,330,278$ & 370,142 \\
\hline & Min & 6,130 & 13,617 & 19,335 & 14,929 & 3,575 \\
\hline & Max & $153,339,255$ & $184,335,443$ & $59,230,704$ & $61,930,835$ & $50,346,424$ \\
\hline \multirow[t]{4}{*}{ Daily Number of Trades } & Mean & 236 & 348 & 174 & 331 & 136 \\
\hline & Median & 84 & 121 & 97 & 142 & 29 \\
\hline & Min & 2 & 4 & 3 & 6 & 2 \\
\hline & Max & 2,120 & 3,512 & 1,156 & 1,549 & 1,111 \\
\hline \multirow{4}{*}{$\begin{array}{l}\text { U.S. Share of Global Volume in } \\
\text { USD (\%) }\end{array}$} & Mean & 7.24 & 100 & 12.64 & 25.45 & 51.12 \\
\hline & Median & 1.90 & 100 & 7.08 & 15.08 & 46.68 \\
\hline & Min & 0.20 & 100 & 0.22 & 0.86 & 0.63 \\
\hline & Max & 99.49 & 100 & 83.38 & 88.94 & 97.94 \\
\hline Sample Size & & 135 & 135 & 69 & 66 & 64 \\
\hline
\end{tabular}




\section{Table 2: European cross-listed stock trading}

This table reports means for the European cross-listed sample (European) and the matched U.S. sample (U.S. Match) and mean differences across the 135 matched pairs of European and U.S. stocks. The overlapping period is when both the home exchange and the NYSE are open; the nonoverlapping period is the equal-length period immediately following the home-exchange close. Intraday volatility is the fiveminute high minus low price, divided by the last trade price. Quoted spread is the offer price minus the bid price, normalized by the quote midpoint and time-weighted. Effective spread is twice the difference between the trade price and the quote midpoint at the time of the trade, normalized by the trade price and volume-weighted. Quoted depth is the time-weighted average depth at the inside quotes. Participation rate is the sum of specialist buys and sells divided by total trading volume.

Data are from the NYSE CT, CQ, and SPET databases. Averages for each stock are calculated over 221 trading days in 2003. Significance tests are based on relative differences (taking the logarithm of each measure before computing standard errors and conducting the t-test for a difference in means) across 135 stocks in each sample and across 135 matched pairs in difference-of-difference tests. Differences that are significant at the $1 \%, 5 \%$, and $10 \%$ levels are designated by $* * *, * *$, and *, respectively.

\begin{tabular}{|c|c|c|c|c|}
\hline & Sample & Overlap & Nonoverlap & $\begin{array}{r}\text { Overlap - } \\
\text { Nonoverlap }\end{array}$ \\
\hline \multicolumn{5}{|c|}{ Panel A: Trading Activity } \\
\hline \multirow[t]{3}{*}{ Share volume } & European & 130,487 & 58,342 & $72,145 * * *$ \\
\hline & U.S. Match & 98,797 & 63,515 & $35,282 * * *$ \\
\hline & Difference & $31,675 * * *$ & $-5,193 * * *$ & $36,868 * * *$ \\
\hline \multirow[t]{3}{*}{ Number of trades } & European & 88 & 55 & $33 * * *$ \\
\hline & U.S. Match & 114 & 85 & $29 * * *$ \\
\hline & Difference & $-26 * * *$ & $-30 * * *$ & $4 *$ \\
\hline \multirow[t]{3}{*}{ Intraday Volatility (bp) } & European & 13.7 & 10.8 & $2.8 * * *$ \\
\hline & U.S. Match & 13.9 & 9.6 & $4.3 * * *$ \\
\hline & Difference & $0.0 * * *$ & $2.0 * * *$ & $-2.0 * * *$ \\
\hline \multicolumn{5}{|c|}{ Panel B: Transaction Costs } \\
\hline \multirow[t]{3}{*}{ Quoted Spread (bp) } & European & 70.6 & 86.3 & $-15.7 * * *$ \\
\hline & U.S. Match & 65.8 & 57.7 & $8.1^{* * *}$ \\
\hline & Difference & $5.0 *$ & $28.8 * * *$ & $-23.8 * * *$ \\
\hline \multirow[t]{3}{*}{ Effective Spread (bp) } & European & 52.5 & 64.1 & $-11.6 * * *$ \\
\hline & U.S. Match & 48.1 & 44.2 & $3.9 * * *$ \\
\hline & Difference & $3.7 * * *$ & $20.2 * * *$ & $-16.5 * * *$ \\
\hline \multicolumn{5}{|c|}{ Panel C: Liquidity Provision } \\
\hline \multirow[t]{3}{*}{ Quoted Depth (shares) } & European & 1,640 & 1,104 & $536 * * *$ \\
\hline & U.S. Match & 769 & 839 & $-71 * * *$ \\
\hline & Difference & $872 * * *$ & $268 * * *$ & $604 * * *$ \\
\hline \multirow[t]{3}{*}{ Participation Rate (\%) } & European & 40.3 & 46.2 & $-5.8 * * *$ \\
\hline & U.S. Match & 42.9 & 37.9 & $4.9^{* * *}$ \\
\hline & Difference & $-2.9 * * *$ & $7.3 * * *$ & $-10.6 * * *$ \\
\hline
\end{tabular}




\section{Table 3: European cross-listed stock effective spread decomposition}

This table reports means for the European cross-listed stock sample (European) and the matched U.S. stock sample (U.S. Match). The overlapping period is when both the home exchange and the NYSE are open; the nonoverlapping period is the equal-length period immediately following the home-exchange close. Effective spread is twice the difference between the trade price and the quote midpoint at the time of the trade. Realized spread is twice the difference between the trade price and the quote midpoint five minutes after the trade. Effective and realized spreads are normalized by the trade price and volume-weighted. Information content is the difference between the effective spread and the realized spread.

Averages for each stock are calculated over 221 trading days in 2003. Significance tests are calculated across 135 stocks in each sample and across 135 matched pairs in difference-of-difference tests. Differences that are significant at the 1\%, 5\%, and 10\% levels are designated by ${ }^{* * *}, * *$, and ${ }^{*}$, respectively.

\begin{tabular}{llcrr}
\hline & Sample & Overlap & Nonoverlap & $\begin{array}{r}\text { Overlap - } \\
\text { Nonoverlap }\end{array}$ \\
\hline \multirow{2}{*}{ Effective Spread (bp) } & & & & \\
& European & 52.5 & 64.1 & $-11.6 * * *$ \\
& U.S. Match & 48.1 & 44.2 & $3.9 * * *$ \\
& Difference & $3.7 * * *$ & $20.2 * * *$ & $-16.5 * * *$ \\
Realized Spread (bp) & & & & $-7.4 * * *$ \\
& European & 32.1 & 39.5 & $2.3 * * *$ \\
& U.S. Match & 24.4 & $17.4 * * *$ & $-9.7 * * *$ \\
Information Content (bp) & Difference & $7.7 * * *$ & & $-4.3 * * *$ \\
& & & 24.6 & $1.5 *$ \\
& European & 20.4 & 22.1 & $-5.8 * * *$ \\
\hline
\end{tabular}




\section{Table 4: European cross-listed stock cross-sectional regressions}

This table reports results from cross-sectional regression analyses of the 135 European cross-listed stocks. Differences are overlapping - nonoverlapping period differences, averaged across 221 days per symbol. The overlapping period is when both the home exchange and the NYSE are open, and the nonoverlapping period is the equal-length time period immediately following the home exchange close. Effective spread is twice the difference between the trade price and the quote midpoint at the time of the trade. Participation rate is the sum of specialist buys and sells divided by total trading volume.

\%TradeEurope is a logit transformation of the percentage of the firm's global equity trading volume that occurred on European exchanges in 2003: $\log [\%$ TradeEurope/(1-\%TradeEurope)]. Home-market development is the natural logarithm of the product of the home market's country indices of shareholder rights from Bhattacharya and Daouk (2002) and law and accounting from LaPorta, Lopez-de-Silanes, Shleifer, and Vishny (1998). Home-market size is the total market capitalization for all firms listed on the home exchange, year-end 2003.

Price is the natural logarithm of the average daily closing price. Firm global market cap is the natural logarithm of the firm's global market capitalization, year-end 2003. Volatility is the high minus low price, divided by the last trade price in the five-minute interval. Quoted depth is the average depth (in 100 shares) at the inside quotes on the NYSE. Quoted spread is the time-weighted average difference between the best offer and best bid. Specialist = BWG (Bear Wagner), FLT (Fleet), LAB (LaBranche), SLK (Spear, Leeds \& Kellogg), and VDM (Van der Moolen) are indicator variables set equal to one if the cross-listed stock is handled by that specialist firm, else zero. All explanatory variables except indicator variables are scaled by their cross-sectional standard deviation, so the coefficient estimate represents the change in the dependent variable for a one-standard-deviation change in the explanatory variable. Data are from the NYSE CT, CQ, SPET, and Non-U.S. Companies databases and from CRSP.

Significance levels are based on robust standards errors adjusted for heteroskedasticity; *** / ** /* denote significance at the $1 \%$ / 5\% / 10\% level.

\begin{tabular}{|c|c|c|c|c|}
\hline \multirow{2}{*}{$\begin{array}{l}\text { Dependent Variable } \\
\text { \%TradeEurope }\end{array}$} & \multicolumn{2}{|c|}{ Effective Spread Difference (bp) } & \multicolumn{2}{|c|}{ Participation Rate Difference (bp) } \\
\hline & $-5.194^{* *}$ & $-5.932 * * *$ & $-1.897^{* *}$ & $-0.772 * *$ \\
\hline Home-market development & $-2.744 *$ & -2.338 & $-1.650 * * *$ & $-1.725^{* * *}$ \\
\hline Home-market size & -2.927 & $-4.827^{* * *}$ & $-2.752^{* * *}$ & $-1.608^{* *}$ \\
\hline Price & 3.196 * & $4.256 * *$ & 0.183 & -0.682 \\
\hline Firm global market cap & $6.418^{* * *}$ & $4.522 *$ & $1.593 *$ & 0.543 \\
\hline Volume difference & & $-4.606^{* *}$ & & $1.286 *$ \\
\hline Trade size difference & & $6.231^{* * *}$ & & -1.270 \\
\hline Volatility difference & & $5.874^{* * *}$ & & $1.344^{* *}$ \\
\hline Quoted depth difference & & $-4.570 * *$ & & -0.872 \\
\hline Quoted spread difference & & -- & & $2.912^{* * *}$ \\
\hline Specialist $=$ BWG & & 8.640 & & -0.169 \\
\hline Specialist $=$ FLT & & 12.732 & & 2.270 \\
\hline Specialist $=\mathrm{LAB}$ & & 10.681 & & -0.313 \\
\hline Specialist $=$ SLK & & 3.347 & & 0.755 \\
\hline Specialist $=$ VDM & & -0.647 & & -1.467 \\
\hline Constant & 45.055 & $59.629^{* *}$ & $50.286^{* * *}$ & $41.360^{* * *}$ \\
\hline Observations & 135 & 135 & 135 & 135 \\
\hline Adj. $R^{2}$ & $33.5 \%$ & $48.5 \%$ & $29.9 \%$ & $45.7 \%$ \\
\hline
\end{tabular}




\section{Table 5: European cross-listed stock trading on home-exchange holidays}

This table reports means for the European cross-listed stocks (Eur_Hols) and the matched U.S. stocks (US_Hols) during home exchange holidays. The overlapping period is when both the home exchange and the NYSE are normally open; the nonoverlapping period is the equal-length period immediately following the home exchange's normal close. Intraday volatility is the five-minute high minus low price, divided by the last trade price. Quoted spread is normalized by the quote midpoint and time-weighted. Effective spread is twice the difference between the trade price and the quote midpoint at the time of the trade, normalized by the trade price and volume-weighted. Quoted depth is the time-weighted average depth at the inside quotes. Participation rate is the sum of specialist buys and sells divided by the total trading volume.

Data are from the NYSE CT, CQ, and SPET databases. Averages for each stock are calculated over the European market holidays in 2003, ranging from two to ten days depending on the home exchange. Significance tests are based on relative differences (taking the logarithm of each measure before computing standard errors and conducting the t-test for a difference in means) across 135 stocks in each sample and across 135 matched pairs in difference-of-difference tests. Differences that are significant at the 1\%, 5\%, and 10\% levels are designated by ***, **, and *, respectively.

\begin{tabular}{|c|c|c|c|c|}
\hline & Sample & Overlap & Nonoverlap & $\begin{array}{r}\text { Overlap - } \\
\text { Nonoverlap }\end{array}$ \\
\hline \multicolumn{5}{|c|}{ Panel A: Trading Activity } \\
\hline \multirow[t]{3}{*}{ Share volume } & Eur_Hols & 81,218 & 51,753 & $30,790 * * *$ \\
\hline & US_Hols & 94,850 & 55,537 & $40,130 * * *$ \\
\hline & Difference & $-15,605 * * *$ & $-5,787 * * *$ & $-9,961$ \\
\hline \multirow[t]{3}{*}{ Number of trades } & Eur_Hols & 68 & 51 & $18 * * *$ \\
\hline & US_Hols & 116 & 80 & $38 * * *$ \\
\hline & Difference & $-51 * * *$ & $-32 * * *$ & $-20 *$ \\
\hline \multirow[t]{3}{*}{ Intraday Volatility (bp) } & Eur_Hols & 12.1 & 8.4 & $3.9 * * *$ \\
\hline & US_Hols & 13.8 & 8.8 & $5.1 * * *$ \\
\hline & Difference & -1.9 & 0.2 & -2.1 \\
\hline \multicolumn{5}{|c|}{ Panel B: Transaction Costs } \\
\hline \multirow[t]{3}{*}{ Quoted Spread (bp) } & Eur_Hols & 85.9 & 68.4 & $16.8^{* * *}$ \\
\hline & US_Hols & 65.6 & 55.7 & $9.9 * * *$ \\
\hline & Difference & $20.1 * * *$ & $14.0 * * *$ & 6.2 \\
\hline \multirow[t]{3}{*}{ Effective Spread (bp) } & Eur_Hols & 55.0 & 50.0 & 6.0 \\
\hline & US_Hols & 42.5 & 42.6 & 0.1 \\
\hline & Difference & $13.5 * * *$ & $10.0 * * *$ & 3.7 \\
\hline \multicolumn{5}{|c|}{ Panel C: Liquidity Provision } \\
\hline \multirow[t]{3}{*}{ Quoted Depth (shares) } & Eur_Hols & 1,132 & 1,234 & $-97 *$ \\
\hline & US_Hols & 834 & 1,028 & $-194 * * *$ \\
\hline & Difference & $302 * * *$ & $222 * * *$ & 82 \\
\hline \multirow[t]{3}{*}{ Participation Rate (\%) } & Eur_Hols & 48.64 & 38.46 & $11.26 * * *$ \\
\hline & US_Hols & 41.67 & 36.19 & $6.01 * * *$ \\
\hline & Difference & $6.79 * * *$ & $4.25 * *$ & 4.68 \\
\hline
\end{tabular}




\section{Table 6: Non-European cross-listed stock trading}

This table reports means for Asian (Asia), Canadian (Can), and Latin American (LatAm) cross-listed stocks. The First 2 hours are 9:30 11:30, the Second 2 hours are 11:30:01 - 13:30 EST. Intraday volatility is the five-minute high minus low price, divided by the last trade price. Quoted spread is the offer price minus the bid price, normalized by the quote midpoint and time-weighted. Effective spread is twice the difference between the trade price and the quote midpoint at the time of the trade, normalized by the trade price and volume-weighted. Quoted depth is the time-weighted average depth at the inside quotes. Participation rate is the sum of specialist buys and sells divided by total trading volume.

Data are from the NYSE CT, CQ, and SPET databases. Averages for each stock are calculated over 221 trading days in 2003.

Significance tests are based on relative differences (taking the logarithm of each measure before computing standard errors and conducting the t-test for a difference in means) across the number of stocks in each sample.

Differences that are significant at the 1\%, 5\%, and 10\% levels are designated by ***, **, and *, respectively.

\begin{tabular}{|c|c|c|c|c|c|c|}
\hline & Sample & $\begin{array}{l}\text { Number of } \\
\text { Stocks }\end{array}$ & $\begin{array}{r}\text { First } \\
2 \text { hours }\end{array}$ & $\begin{array}{l}\text { Second } \\
2 \text { hours }\end{array}$ & \multicolumn{2}{|c|}{$\begin{array}{r}\text { First - Second } \\
2 \text { hours }\end{array}$} \\
\hline \multicolumn{7}{|c|}{ Panel A: Trading Activity } \\
\hline \multirow[t]{3}{*}{ Share volume } & Asia & 69 & 111,055 & 61,023 & 50,032 & **** \\
\hline & Can & 66 & 198,301 & 109,891 & 88,410 & $* *$ \\
\hline & LatAm & 64 & 57,004 & 42,789 & 14,215 & $* * *$ \\
\hline \multirow[t]{3}{*}{ Number of trades } & Asia & 69 & 59 & 44 & 15 & $* * *$ \\
\hline & Can & 66 & 117 & 83 & 34 & $* * *$ \\
\hline & LatAm & 64 & 43 & 36 & 7 & $* * *$ \\
\hline \multirow[t]{3}{*}{ Intraday Volatility (bp) } & Asia & 69 & 12.1 & 8.4 & 3.7 & $* * *$ \\
\hline & Can & 66 & 14.7 & 8.9 & 5.8 & $* * *$ \\
\hline & LatAm & 64 & 14.8 & 12.4 & 2.4 & $* * *$ \\
\hline \multicolumn{7}{|c|}{ Panel B: Transaction Costs } \\
\hline \multirow[t]{3}{*}{ Quoted Spread (bp) } & Asia & 69 & 75.6 & 66.5 & 9.1 & $* * *$ \\
\hline & Can & 66 & 39.5 & 33.3 & 6.2 & $* * *$ \\
\hline & LatAm & 64 & 159.4 & 140.0 & 19.4 & $* * *$ \\
\hline \multirow[t]{3}{*}{ Effective Spread (bp) } & Asia & 69 & 57.4 & 49.8 & 7.6 & $* * *$ \\
\hline & Can & 66 & 31.8 & 25.6 & 6.1 & $* * *$ \\
\hline & LatAm & 64 & 109.6 & 99.3 & 10.3 & $* * *$ \\
\hline \multicolumn{7}{|c|}{ Panel C: Liquidity Provision } \\
\hline \multirow[t]{3}{*}{ Quoted Depth (shares) } & Asia & 69 & 18,172 & 20,077 & $-1,905$ & $* * *$ \\
\hline & Can & 66 & 24,959 & 28,894 & $-3,935$ & * \\
\hline & LatAm & 64 & 12,916 & 14,623 & $-1,708$ & $* * *$ \\
\hline \multirow[t]{3}{*}{ Participation Rate (\%) } & Asia & 69 & 45.70 & 41.10 & 4.54 & $* * *$ \\
\hline & Can & 66 & 33.46 & 30.21 & 3.25 & $* * *$ \\
\hline & LatAm & 64 & 45.98 & 40.32 & 5.66 & *** \\
\hline
\end{tabular}


Figure 1: Comparison of NYSE and European exchange trading hours

Comparison of trading hours for the NYSE and the 14 European exchanges that are the home exchanges for the 135 European cross-listed stocks. Number of stocks from each home exchange is in parentheses.

Stock Exchange Trading Hours

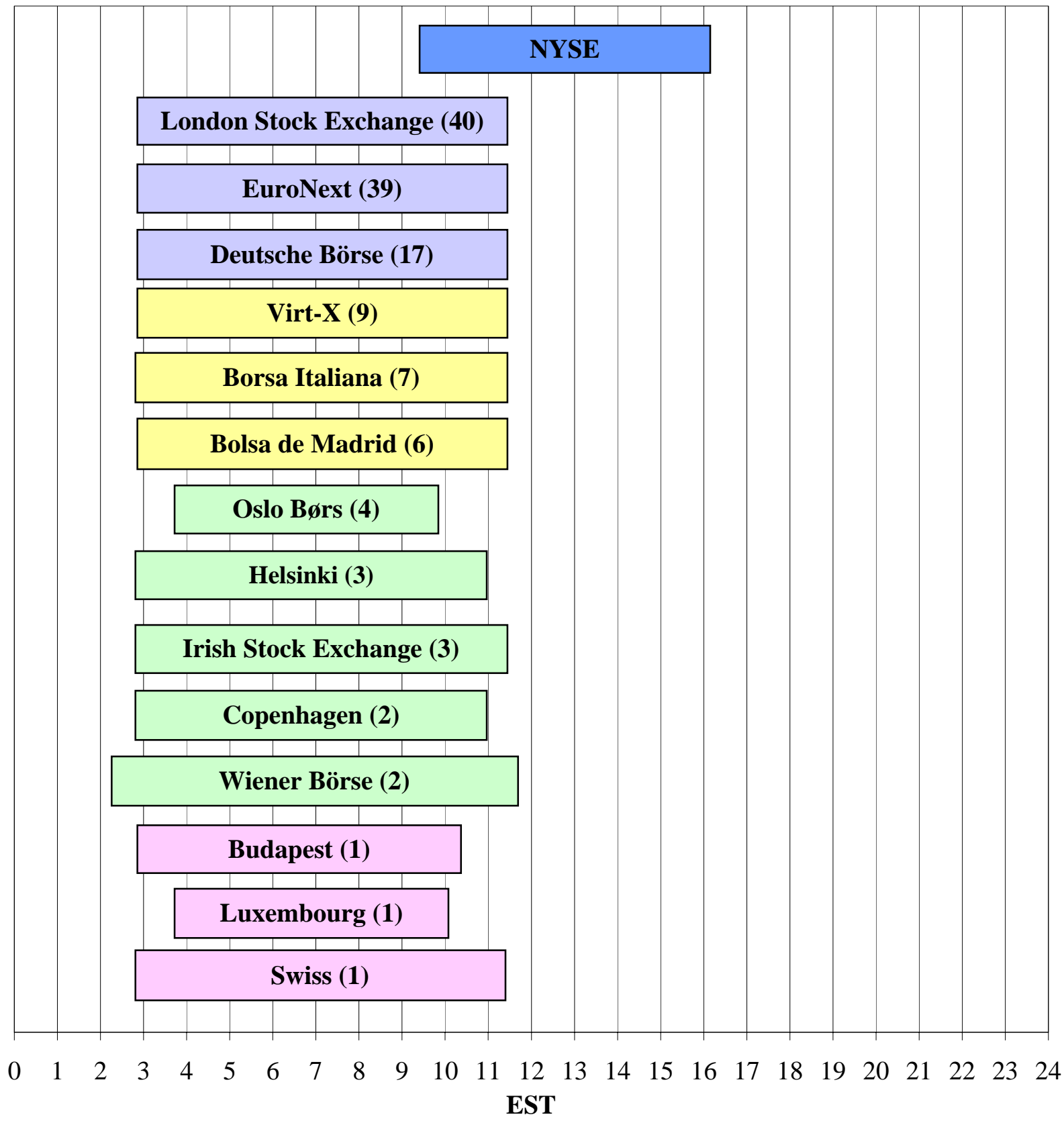

